\title{
O conceito de classe social no marxismo: correntes e atualidade
}

\section{The concept of social class in the marxism: currents and present}

\author{
Rafael Grohmann ${ }^{1}$
}

\section{Resumo}

O artigo discute a relevância e a atualidade do conceito de classe e se propõe a pensar o conceito de classe social em algumas correntes do marxismo, a partir de: i) o próprio Marx; ii) Nico Poulantzas; iii) Adam Przeworski; iv) Erik Olin Wright e o Marxismo Analítico; e v) Edward Palmer Thompson e os Estudos Culturais de Birmingham.

Palavras-chave: Classe. Marx. Marxismos.

\section{Abstract}

This article discusses the relevance and importance of the current class concept and proposes to think about the concept of social class in some currents of marxism, from: i) Marx; ii) Nico Poulantzas; iii) Adam Przeworski; iv) Erik Olin Wright and Analytical Marxism; and v) Edward Palmer Thompson and Cultural Studies in Birmingham.

Keywords: Class. Marx. Marxism.

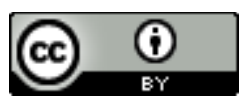

Esta obra foi licenciada com uma Licença Creative Commons - Atribuição 3.0 Não Adaptada.

\section{Introdução}

O conceito de classe social não é estudado hoje do mesmo modo como há 30 anos, seja pelo deslocamento da pesquisa para outras identidades e sujeitos coletivos a partir de categorias como raça, gênero ou etnia, seja somente por negar categorias coletivas como passíveis de explicar a realidade. O conceito de classe, para Therborn (2012a, p. 118), deslocou-se "por sua derrota na luta de classes capitalista, mas também porque os desenvolvimentos da demografia pós-industrial o desalojaram de sua centralidade teórica ou geográfica”.

\footnotetext{
1 Universidade de São Paulo (USP). Professor do Complexo Educacional FMU-FIAM-FAAM e integrante do Centro de Pesquisas em Comunicação e Trabalho (CPCT / ECA-USP). E-mail: rafaelng@uol.com.br

Cad. de Pesq. Interdisc. em Ci-s. Hum-s. Florianópolis, Santa Catarina, Brasil, ISSN 1984-8951 v.14, n.105, p.3-18, ago/dez 2013
} 
Pinto (2008) afirma que há encobrimentos lexicais que tendem a negar conceitos como "exploração" ou "classe social", despolitizando o debate e ocultando as dinâmicas do conflito. Pois, se toda fluidez e toda interação são exaltadas nessa estação da moda, há conceitos que são colocados como "mortos-vivos" (BECK, 1999), como se relegados ao segundo plano do cenário científico; como se fossem peças de museus ou ultrapassados para a compreensão da realidade atual. Ao lado de "ideologia", o conceito de classe social é um desses exemplos. Há discursos, como o liberal (HAYEK, 1990), que afirmam que as classes sociais não existem, e o que existem são indivíduos soltos no mundo.

Cria-se, então, um "mito de uma sociedade sem classes", como diz Munt (2000). Segundo Harvey (2013, p. 324), "classe é uma categoria que os poderes instituídos não querem que ninguém leve a sério". Ele afirma que temos de perder o medo de falar e de mobilizar estratégias em torno da "guerra de classes". Para Murdock (2009, p. 33),

\begin{abstract}
a classe pode ter sido abolida retoricamente em muitos textos, mas uma quantidade impressionante de evidência empírica confirma que ela permanece como uma força essencial para modelar a maneira como vivemos hoje. É extremamente irônico que a 'virada' teórica pós-moderna, que impulsionou questões de identidade, consumo e diferença para o centro da atenção acadêmica, coincidiu quase exatamente com a revolução neoliberal em diretrizes sociais e econômicas. É fácil 'pensar que a classe não importa' se você permanece relativamente 'não-afetado por privações e exclusões que ela causa'.
\end{abstract}

Ou, como diz Eagleton (2012, p. 134), não é "só porque os presidentes de empresa hoje podem usar tênis, ouvir Rage Against the Machine e implorar a seus empregados para os chamarem de 'fofos'", que a classe social foi varrida da Terra. Therborn (2012b), em artigo recente na revista New Left Review, se questiona se haverá um "século de classe média", principalmente, considerando o papel dos BRICs na reconfiguração da geopolítica contemporânea. "A personalidade social do novo século ainda está para ser determinada, mas o conceito de classe certamente será de vital importância" (THERBORN, 2012b, p. 37). Ou seja, parece haver um renovado interesse na questão de classe.

Nos últimos anos, o conceito de classe retorna à cena com certo verniz, com a imagem do "Brasil novo". Com o crescimento econômico do país e o incentivo ao crédito, uma parcela da população viu aumentar sua renda e seu poder de consumo. Com isso, houve o aparecimento de termos como "nova classe média" ou "nova 
classe C". Neri (2010), atual presidente do Instituto de Pesquisa Econômica Aplicada (IPEA), faz um ode à mobilidade social que propiciou a ascensão econômica de milhares de brasileiros, o "lado brilhante da base da pirâmide", em suas próprias palavras. ${ }^{2}$ Com isso, o termo ganhou força nos campos da mídia e da academia, mas não em termos de "conflito" ou "luta de classes", mas, principalmente, de "consumo".

Os profetas do "ócio criativo" e que falam que "todo trabalho vira lazer" também estão falando sobre classes. O livro "A Ascensão da Classe Criativa", de Florida (2011), coloca a "criatividade" como um ponto central para definir uma nova classe, que tem como dois subcomponentes: "o centro Hipercriativo e os profissionais criativos". O livro tenta mostrar como há, no mundo de hoje, "uma nova estrutura de classes". Cabe, então, indagar qual o papel da "criatividade" em definir uma classe. Entretanto, interessa-nos o que Florida (2011, p. 8) diz: "essa nova classe pode não ser tão claramente definida quanto a classe trabalhadora da era industrial, mas demonstra cada vez mais coerência".

O que queremos dizer é: o conceito de classe não é estático, e as estruturas de classe não são as mesmas da época de Marx, Weber, ou até mesmo de Bourdieu. Mas será que as "teorias de classe" não tem "muita utilidade" para entender o conceito na atualidade, como sugere Florida (2011)? Será que tudo pode ser reduzido, no mundo de hoje, à "classe criativa"? E classe continua a ser uma categoria explicadora da realidade?

Segundo Therborn (2012a), a classe continua a ser a principal categoria em muitos campos, seja na corrente sociológica dominante, nas teorias sobre mobilidade social, nos estudos de práticas de consumo inspirados por Bourdieu, nos estudos que buscam entrelaçar classe, raça e gênero. Mas, e no marxismo? Como a categoria de classe é considerada? O objetivo deste artigo é fazer uma exploração inicial de como alguns marxistas e suas correntes respondem ao problema de classe.

\footnotetext{
${ }^{2}$ O subtítulo original da pesquisa, que pode ser encontrada no site da Fundação Getúlio Vargas (FGV), é o "lado brilhante dos pobres". A título de provocação, pode-se fazer uma indagação ao analisar esse enunciado: os pobres só teriam um lado "brilhante" quando consomem? De resto, eles seriam considerados opacos, invisíveis? Pesquisa disponível em: <http://www.cps.fgv.br/ibrecps/ncm2010/NCM_Pesquisa_FORMATADA.pdf>. Acesso em: 11 mai. 2013.
}

Cad. de Pesq. Interdisc. em Ci-s. Hum-s. Florianópolis, Santa Catarina, Brasil, ISSN 1984-8951 v.14, n.105, p.3-18, ago/dez 2013 


\title{
1 Marx, marxismo(s) e classes sociais
}

A noção de classe social é mais presente enquanto "conceito" no marxismo e em suas diferentes correntes, do que propriamente na obra Marxiana, em que se vê mais o conceito aplicado do que necessariamente a sua definição sistemática do conceito. "O capítulo destinado à teoria de classes no livro III de O Capital é interrompido justamente quando Marx tratava de explicitar sua definição de classe" (SANTOS, 2002, p. 81).

Para a perspectiva marxista, as classes são atores históricos e forças sociais. As relações capitalistas de produção geram um tipo muito específico de estruturas de classe. Deste modo, as relações de classe são determinadas pelas relações sociais de produção, considerando como fundamentais as relações de propriedade e a exploração. "A conceitualização de classe remete essencialmente à posição (objetiva e subjetiva) que os indivíduos ocupam no mundo da produção social" (ANTUNES, 2005, p. 103).

Para Eagleton (2012, p. 134), “o Marxismo não define classe em termos de estilo, status, renda, sotaque ou preferência pessoal de ornar as paredes com patos ou Degas": o mais importante é seu lugar no modo capitalista de produção. A análise da diferenciação social, para o marxismo, não se separa da análise dos conflitos e das lutas. Não se trata somente de uma questão de renda, prestígio ou instrução.

Há, aí, uma centralidade do mundo econômico, mas que deve ser entendido dialeticamente e não como algo reducionista. Para Eagleton (2012, p. 101),

\begin{abstract}
a afirmação de que para Marx tudo é determinado pela 'economia' é uma supersimplificação absurda. O que molda o curso da história, a seu ver, é a luta de classes; e as classes não são redutíveis a fatores econômicos. É verdade que Marx encara as classes, quase sempre, como grupos de homens e mulheres que ocupam o mesmo lugar dentro de um modo de produção, mas é sintomático que falemos de classes sociais, e não de classes econômicas. Marx escreve sobre as relações 'sociais' de produção, bem como sobre revolução 'social'. Se as relações sociais de produção têm prioridade sobre as forças de produção, fica difícil ver como algo francamente rotulado como 'o econômico' possa ser o motor primordial da história.
\end{abstract}

A análise de classes é um dos pontos cruciais do marxismo. Marx (1977a) dizia que muitos autores antes dele já haviam falado de classe. Uma das novidades 
que ele diz trazer é demonstrar que a existência das classes está ligada somente a determinadas fases de desenvolvimento da produção. Mas o que definiria o conceito de classe é o lugar na produção, considerando a "luta de classes".

\begin{abstract}
Marx declara no Manifesto Comunista que "a história de toda a sociedade existente anteriormente é a história da luta de classes". Claro que não se deve interpretá-lo ao pé da letra. Se o fato de eu escovar os dentes na quarta-feira passada conta como parte da história, é difícil considerar tal ato como uma questão de luta de classes. Executar determinado arremesso no críquete ou ter obsessão patológica por pinguins não é fundamentalmente relevante para a luta de classes (EAGLETON, 2012, p. 30).
\end{abstract}

Ou seja, a exclusividade da teoria marxista não é a observação de que a sociedade é dividida em classes, mas as fronteiras de classe que são tomadas como cruciais para o marxismo. Pois, o que, no "Manifesto do Partido Comunista" (MARX, 1996), era uma divisão entre "burgueses" e "proletários", ganha contornos mais refinados em "O 18 Brumário de Luis Bonaparte" (MARX, 1997), e em "As Lutas de Classe na França de 1848 a 1850" (MARX, 1977b), em que o autor chega a citar sete classes, dando importância à questão do fracionamento de classes, às diferentes formas de propriedade, às diferentes maneiras de pensar e às condições sociais. É importante salientar que, no marxismo, a classe só se efetiva na relação: só há dominação com dominadores e dominados - trata-se de relações sociais.

Em 18 Brumário, Marx (1997) procura operacionalizar a análise de classe no processo político, com uma análise de conjuntura, em que se deve considerar o movimento e a história, não de forma determinista, pois as classes se formam nas lutas de classe, e é preciso considera-las também como atores políticos. Ele atribui uma centralidade aos chamados "porta-vozes", como partidos, sindicatos ou igrejas, por onde seriam reverberados os interesses de classe, como uma representação de classe. Estes representantes não atuariam como porta-vozes diretos, mas como portadores de uma visão de mundo que ajuda a contribuir com a reprodução dos valores. Ou seja, os interesses de classe também possuem uma dimensão ideológica. A classe dominante, assim o é porque suas ideias dominam, fato que não invalida a existência de outras ideias, muitas vezes ainda não organizadas como ideias contra-hegemônicas.

Eagleton (2012), como vimos acima, pretende mostrar a atualidade do pensamento marxiano, e como o conceito de classe social continua atual. Cad. de Pesq. Interdisc. em Ci-s. Hum-s. Florianópolis, Santa Catarina, Brasil, ISSN 1984-8951 v.14, n.105, p.3-18, ago/dez 2013 
Compreender a dinâmica da sociedade, com suas contradições e movimentos, significa também entender que as classes alteram a sua composição o tempo todo: não podemos retificar o conceito de classe. "A classe operária não deixa de interessar aos marxistas no momento em que passa a desfrutar de banheiros dentro da casa ou possuir TVs em cores. É seu lugar no modo capitalista de produção que constitui o ponto mais decisivo" (EAGLETON, 2012, p. 138).

A partir da consideração do lugar no modo capitalista de produção como central para o conceito de classe, as várias correntes Marxistas desenvolveram especificidades em suas análises de classe, e, em algumas vezes, procurando pensar as formações de classe. Mas, como esse conceito aparece em algumas correntes do marxismo?

\section{0 conceito de classe social em Poulantzas, Przeworski, Wright e Thompson}

Sem a intenção de esgotar o assunto, pretendemos apresentar como alguns autores Marxistas resolvem o problema da classe social. São eles: Nico Poultanzas, Adam Przeworski, Erik Olin Wright e Edward Palmer Thompson, juntamente com os Estudos Culturais Britânicos.

Uma das grandes contribuições que Poulantzas (1973) traz à análise marxista da classe é a consideração de elementos não econômicos das classes sociais, como os políticos e ideológicos. "As classes sociais são grupos de agentes sociais, homens, definidos, principalmente, mas não exclusivamente por sua posição no processo de produção" (POULANTZAS, 1973, p. 7). Isto é, há um impacto independente das relações ideológicas, econômicas e políticas sobre as classes. O autor considera que a definição se dá a partir da posição no conjunto das práticas sociais, propondo a volta da conceituação de classe a partir da divisão social do trabalho.

A classe, para Poulantzas (1973), deve ser pensada como uma relação, não como algo definido exclusivamente pelas relações de produção, pois nenhum ocupante de lugar é classe. "A delimitação das classes não se resume assim jamais a um simples estudo 'estático' das estatísticas: depende do processo histórico" (POULANTZAS, 1973, p. 39). 
Outro mérito de Poulantzas é o de conceituar alguns termos a partir do conceito de classe social, como "classe detentora", "categoria social", "determinação de classe", "posição de classe", "interesses de classe" e "fração de classe". Para ele, o que distingue o marxismo de outas concepções sociológicas é estudar, observar e distinguir as frações da mesma classe.

As críticas a Poulantzas se relacionam com a sua ligação com o estruturalismo e sua ligação com Louis Althusser pois, para Poulantzas (1973), a classe social deve ser pensada como um efeito do conjunto das estruturas sobre os agentes, considerando as estruturas de classes. "As diferentes classes são identificadas de acordo com a sua relação funcional com o modo capitalista de produção como um todo" (CROMPTON, 2008, p. 31). Critica-se, então, a taxonomia utilizada por Poulantzas, o que traria um formalismo inexistente na teoria marxista.

Outras explicações para o conceito de classe social vêm do chamado marxismo analítico, que, como diversas correntes, pretende "reconstruir o marxismo" (WRIGHT; LEVINE; SOBER, 1993), mas tentando atualizar e trazer clareza "às formulações causais do marxismo clássico, de acordo com os procedimentos da filosofia analítica" (PERISSINOTTO, 2010, p. 125).

Os principais autores, como Elster, Przeworski e Wright, buscam entender problemas da emancipação humana e da exploração a partir de conceitos como ação coletiva, formação de classe e a conceituação das classes médias. "Os seus principais representantes continuam a sustentar um compromisso com a maleabilidade histórica das preferências humanas, em função da formação social do indivíduo" (PERISSINOTTO, 2010, p. 124). Para eles, o marxismo deve ter a lógica das ciências, e seus autores desconsideram a dialética, o que faz, muitas vezes, serem questionados como marxistas "legítimos".

No entanto, há muitas divergências dentro da própria corrente, podendo-se questionar se, de fato, trata-se de uma "escola". Uma das problemáticas caras para Elster e Przeworski é o individualismo metodológico. "A ideia básica do individualismo metodológico é que, em última instância, quem age não são 'as classes', 'o Estado', 'os grupos sociais', mas os indivíduos. São eles os responsáveis pelas ações, e, portanto, pelos fenômenos sociais" (PERISSINOTO, 2010, p. 120). Mesmo assim, o marxismo analítico compreende a importância das relações de poder e da ação coletiva entre os atores. 
Com relação ao conceito de classe, Przeworski (1989) procura um caminho intermediário entre o "estruturalismo" de Poulantzas e o "historicismo" de Thompson, procurando compreender o processo de formação de classes enquanto atores coletivos, pois as classes só se formariam no processo de lutas, utilizando-se do individualismo metodológico. Para ele, desse modo, a função da análise de classe é identificar condições e consequências objetivas das lutas concretas. Assim, as lutas de classes se tornam um princípio metodológico ou tautológico em seu pensamento, é algo dado a priori.

Por isso, a análise de classes não deveria limitar-se a especificar os lugares que as pessoas ocupam no sistema de produção, o que Bourdieu (1999) chamaria de "classes no papel", mas observar como se dão essas formações de atores coletivos na "vida real", ou como esses "ocupantes de lugares" tornam-se uma coletividade para realização de seus interesses objetivos. O problema é que as descrições empíricas de "posições socioeconômicas" tornem-se independentes da compreensão histórica. Essa formação de classe não pode ser entendida como uma transição entre "classe-em-si" e "classe-para-si", e o autor defende a seguinte tese: "as classes não são determinadas unicamente por quaisquer posições objetivas porque constituem efeitos de lutas, e essas lutas não são determinadas exclusivamente pelas relações de produção" (PRZEWORSKI, 1989, p. 86). Além disso, Przeworski (1989) considera que, ao analisar o processo de formação de classes, de uma forma empírica, podemos observar contradições entre a posição de classe representada no processo produtivo e as visões de mundo.

Para Przeworski (1989), nem mesmo as relações de exploração determinam por si próprias um padrão exclusivo de formação de classes. E, em especial, as estratégias baseadas em definições amplas de classe operária diminuem a relevância da classe e originam outras divisões como bases para identificação e organização coletiva. Não há, entretanto, alguma indicação em Przeworski de como operacionalizar o conceito, diferentemente de Wright (1997), que faz uma "cartografia das classes sociais", compreendendo a "estrutura das classes". Desse modo, pode-se dizer que ele não é tão distante de Poulantzas, ao tentar categorizar e classificar as classes - trata-se de conceitos essencialmente classificatórios. Uma das críticas que se faz a Wright é o fato de focar mais na estrutura de classes do que na análise das formações de classe, podendo-se indagar se esse tipo de análise 
diluiria a dimensão política da análise de classe, mesmo que Wright (1997) já diga que toda análise de classe já é, a priori, política.

A literatura marxista mais recente tem-se limitado, em geral, a mapear a
estrutura de classe das sociedades capitalistas avançadas e a redefinir o
conceito de classe de modo que se adequasse melhor à realidade dessas
sociedades. Como pouco ou quase nada se diz sobre o processo por meio
do qual a classe se transforma em ator político, parece que o mapeamento
da estrutura de classe constitui-se em um fim em si mesmo, sem que se
estabeleça nenhuma conexão entre ela e o comportamento de classe.
(PERISSINOTO, 2011, p. 202).

Cabe também ressaltar que, para Wright, a classe não é a causa mais importante dos fenômenos sociais, pois as relações de gênero, por exemplo, são autônomas em relação à noção de classe.

As posições de classe, para Wright (1997), são conceituadas a partir das relações sociais de produção, e não a partir das relações técnicas de produção funda-se aí a diferença entre "classe" e "ocupação". Com isso, ela pode ser analisada a partir de três aspectos relacionados ao controle: controle em relação aos meios de produção, aos investimentos e ao processo de acumulação e ao poder de trabalho. Assim, cria-se uma tipologia de classe central, sendo as três principais classes, para ele (1997), a burguesia, o proletariado e a pequena burguesia. É a partir dessa tipologia "básica" que Wright estrutura o seu mapa de classes.

Outro conceito central de Wright para explicar a noção de classe é o de exploração, pois, segundo ele, trata-se de um conceito mais explicativo que o de dominação - um conceito mais restrito que possibilita compreender os vínculos entre a análise de situações de classe e a análise dos interesses objetivos, principalmente a exploração baseada nas relações de produção. As classes, então, são definidas a partir de um mapa estrutural de interesses materiais comuns baseados na exploração. Como afirma Santos (2002, p. 43),

Wright aponta as vantagens do conceito de classe centrado na exploração. A abordagem do problema dos interesses objetivos de classe fica mais clara, pois essa noção adquire um conteúdo mais materialista e histórico ao vincular-se à propriedade efetiva de elementos das forças produtivas, cujo desenvolvimento imprime aos sistemas de classe a sua trajetória histórica. As diferenças qualitativas entre os tipos de estruturas de classe ficam melhor demarcadas. As classes médias são caracterizadas pelos mesmos critérios de base que definem as classes fundamentais. A exploração, por fim, representa um dos mecanismos centrais por meio dos quais a estrutura de classes explica o conflito de classes. 
A partir disso Wright (1997) procura entender o problema das "classes médias" e conceitua o termo "localizações de classe", e afirma a possibilidade de haver localizações contraditórias dentro das relações de classe. Com isso, difere-se do conceito de "frações de classe" de Poulantzas (1973). Os sujeitos das classes médias podem partilhar características relacionais de duas classes sociais. Ele coloca nessa definição gerentes, supervisores, empregados semi-autônomos e pequenos empregadores. Segundo Wright (1997), por exemplo, os administradores deveriam ser vistos ao mesmo tempo como membros da classe trabalhadora, na medida em que são trabalhadores assalariados dominados por capitalistas e como membros da classe capitalista, por conta de seu controle sobre a produção. Outros conceitos centrais à tipologia de classes de Wright são: emancipação, localização distribucional, oportunidades de vida e variação histórica.

Já no campo dos Estudos Culturais, também alinhado ao materialismo histórico, os "pais fundadores" (MATTELART; NEVEU, 2004) de Birmingham colocaram a noção de classe como central para a análise do popular, das sociabilidades e da relação com a mídia, como Thompson (1987), Hoggart (1973) e Willis (1991), entendendo o conceito a partir da "cultura vivida". Ou seja, não se trata de fazer um mapa de classes a priori, como em Wright, mas a classe simplesmente "acontece".

"Por classe, entendo um fenômeno histórico, que unifica uma série de acontecimentos díspares e aparentemente desconectados, tanto na matéria-prima da experiência como na consciência" (THOMPSON, 1987, p. 9). Não se trataria de uma estrutura ou de uma categoria, mas, prioritariamente, de algo que ocorre nas relações humanas e que é histórica, e enquanto histórica deve-se levar em conta as transformações vividas por esses sujeitos. Thompson (1987) não enxerga a classe como uma "estrutura", nem como uma "categoria", mas como algo que ocorre puramente nas relações humanas e que precisa estar encarnada em sujeitos reais. "A classe operária não surgiu tal como o sol, numa hora determinada. Ela estava presente ao seu próprio fazer-se" (THOMPSON, 1987, p. 9).

A noção de classe, então, se dá a partir da relação histórica e na relação entre sujeitos sociais, e não como "coisa matemática", sendo que a única definição plausível, para o autor, é a de classe como homens enquanto vivem sua própria história. 
Não podemos ter amor sem amantes, nem submissão sem senhores rurais e camponeses. A classe acontece quando alguns homens, como resultado de experiências comuns (herdadas ou partilhadas), sentem e articulam a identidade de seus interesses entre si, e contra outros homens cujos interesses diferem (e geralmente se opõem) dos seus (THOMPSON, 1987, p. 10).

A noção de "experiência" também é central para a compreensão do conceito de classe em Thompson, sendo que ela é "determinada pelas relações de produção em que os homens nasceram ou entraram involuntariamente" (THOMPSON, 1987, p. 2010). Segundo Therborn (2012a, p. 118-119), "problematizar a identidade de classe como uma ação de classe que deriva diretamente da experiência [...] foi uma maneira de ajustar o foco da análise de classe".

A partir disso, a consciência de classe é a encarnação dessas experiências em termos culturais, ou seja, em sistemas de valores, instituições, tradições e ideias. Pode haver experiências semelhantes entre classes, no entanto, não se pode ter nenhuma lei. "A consciência de classe surge da mesma forma em tempos e lugares diferentes, mas nunca exatamente da mesma forma" (THOMPSON, 1987, p. 10).

Seus companheiros de Birmingham tendem a concordar com essas afirmações, a partir de uma abordagem culturalista e historicista de classe, com influências, principalmente de Antonio Gramsci, a partir de seus conceitos de "intelectual orgânico" e "hegemonia". Para Gramsci (2000), todas as pessoas são intelectuais, no entanto, não são todos os sujeitos que exercem essa função na sociedade. "O intelectual orgânico do proletariado é aquele que, enquanto especialista, desdobra-se num ser político" (GOMES, 2004, p. 140), como construtor, organizador e "persuasor" permanente. Segundo Cevasco (2003), o projeto dos Estudos Culturais era forjar um novo tipo de intelectual orgânico e se afastar das tarefas habituais dos intelectuais tradicionais. Esse intelectual orgânico deve estar, por um lado, na vanguarda do trabalho intelectual teórico e deve transmitir suas ideias à classe intelectual.

Para Hoggart (1973), por exemplo, pode-se definir a classe trabalhadora, mas isso não significa esquecer as múltiplas e sutis diferenças e distinções de classe (ou frações de classe) entre os seus membros. O que interessa, portanto, aos Estudos Culturais é entender a classe a partir do contexto definido dos sujeitos sociais a partir de suas relações. Não se trata somente de reprodução, mas os sujeitos agem e "vivem seu destino de classe", como explica Willis (1991, p. 12),

Cad. de Pesq. Interdisc. em Ci-s. Hum-s. Florianópolis, Santa Catarina, Brasil, ISSN 1984-8951 v.14, n.105, p.3-18, ago/dez 2013 


\begin{abstract}
a identidade de classe não é verdadeiramente reproduzida até que tenha passado de forma apropriada pelo indivíduo e pelo grupo, até que tenha sido recriada no contexto daquilo que parece ser uma escolha pessoal e coletiva. As pessoas realmente vivem (e não simplesmente tomam emprestado) seu destino de classe quando aquilo que é dado é re-formado, reforçado e aplicado a novos propósitos.
\end{abstract}

De um modo geral, podemos perceber que a partir das definições mínimas de classe no marxismo cada uma das correntes ou "subcorrentes" dão respostas diferentes a partir de suas concepções, sendo impossível um consenso. No entanto, o que poderia ser a crise do conceito de classe no Marxismo é onde se encontra a sua maior vitalidade: trata-se de compreender a sociedade e essas classes em movimento. Segundo Eagleton (2012, p. 46),

quem estuda Marx tem liberdade para escolher que ideias em sua obra parecem mais plausíveis. Apenas os marxistas fundamentalistas encaram essa obra como escritura sagrada, e hoje eles existem em menor número do que os fundamentalistas cristãos.

\title{
Considerações finais
}

Este texto procurou apresentar alguns conceitos de classe para alguns autores marxistas, bem como a vitalidade da análise do conceito de classe no marxismo. Mas, a maioria das teorias aqui apresentadas foi formulada até a década de 80 (no máximo, podemos falar de Wright escrevendo até hoje). Não se trata de um debate fechado, pois quem pretende analisar a classe dentro do campo marxista não pode ignorar, por exemplo, o trabalho de Max Weber (a partir das distinções entre classe e status, por exemplo) e Pierre Bourdieu (a partir da multidimensionalidade do conceito de classe, por exemplo) cujas teorias pretendemos analisar em trabalhos futuros, considerando o papel conceitual das classes sociais atualmente.

Além dessa questão conceitual, é preciso entender o papel de classe na sociedade contemporânea, abarcando a complexidade das identidades dos sujeitos. Como diz Lahire (2006), um pupilo de Bourdieu, "não se pode ser branco, macho, heterossexual e membro da classe média, e apesar de tudo isso, interessar-se pelo rap?". Focalizar a pesquisa no conceito de classe não quer dizer esquecer os 
atravessamentos de classe pelas outras identidades, mas ver a partir do olhar de classe o que esses atributos significam para a formação dos sujeitos coletivos.

A partir dos autores aqui apresentados, podemos considerar que entender a noção de classe a partir de Marx e do marxismo é compreender essa formação de sujeitos coletivos, a "luta de classes" e as dimensões da exploração e da emancipação. Isso é de crucial importância em um mundo onde a "representação simbólica de classe" não se dá somente pelos "porta-vozes" tradicionais, mas há uma "midiatização" (HJAVARD, 2012) das classes sociais, que compreende a crescente influência midiática nas instituições e nas interações sociais e culturais. As classes estão nos institutos de pesquisa, nas revistas, nas novelas, nos aplicativos de celular, nas redes sociais, nos blogs, na moda e na publicidade, como uma "explosão de classes midiatizadas" capazes de dotar de sentido e significado às interações e as práticas de trabalho e de consumo dos sujeitos. 


\section{Referências}

ANTUNES, R. O Caracol e sua Concha: ensaios sobre a nova morfologia do trabalho. São Paulo: Boitempo, 2005.

BECK, U. A Sociedade de Risco. São Paulo: Ed. 34, 1999.

BOURDIEU, P. O Poder Simbólico. Rio de Janeiro: Bertrand Brasil, 1999.

CEVASCO, M. E. Dez Lições Sobre Estudos Culturais. São Paulo: Boitempo, 2003.

CROMPTON, R. Class and Stratification. Cambridge: Polity, 2008.

EAGLETON, T. Marx estava certo. Rio de Janeiro: Nova Fronteira, 2012.

FLORIDA, R. A Ascensão da Classe Criativa. Porto Alegre: L\&PM, 2011.

GOMES, I. Efeito e Recepção. São Paulo: E-Papers, 2004.

GRAMSCI, A. Cadernos do Cárcere. Rio de Janeiro: Civilização Brasileira, 2000.

HARVEY, D. Para Entender O Capital. São Paulo: Boitempo, 2013.

HAYEK, F. A. O Caminho da Servidão. Rio de Janeiro: Instituto Liberal, 1990.

HJARVARD, S. Midiatização: teorizando a mídia como agente de mudança social e cultural. Matrizes, São Paulo, v. 5, n. 2, p. 53-91, jan./jun. 2012.

HOGGART, R. As Utilizações da Cultura: aspectos da vida cultural da classe trabalhadora. Lisboa: Ed. Presença, 1973.

LAHIRE, B. A Cultura dos Indivíduos. Porto Alegre: Artmed, 2006.

MARX, K. Carta a J. Weydemeyer em New York, 5 de março de 1852. In: MARX, K.; ENGELS, F. Obras Escolhidas. São Paulo: Alfa Ômega, 1977a. 
MARX, K. As Lutas de Classe na França de 1848 a 1850. In: MARX, K.; ENGELS, F. Obras Escolhidas. São Paulo: Alfa Ômega, 1977b.

MARX, K. Manifesto do Partido Comunista. Petrópolis: Vozes, 1996.

MARX, K. O 18 Brumário de Luís Bonaparte. Rio de Janeiro: Paz e Terra, 1997.

MATTELART, A.; NEVEU, E. Introdução aos Estudos Culturais. São Paulo: Parábola, 2004.

MUNT, S. Cultural Studies and Working Class: subject to change. London: Cassell, 2000.

MURDOCK, G. Comunicação Contemporânea e Questões de Classe. Matrizes, ano 2, n. 2, p. 31-56. 2009.

NERI, M. A Nova Classe Média: o lado brilhante dos pobres. Relatório de Pesquisa. Rio de Janeiro: CPS/FGV, 2010. Disponível em:

$<$ http://www.cps.fgv.br/ibrecps/ncm2010/NCM Pesquisa FORMATADA.pdf>.

Acesso em 25 jul. 2013.

PERISSINOTTO, R. Marxismo e Ciência Social: um balanço crítico do marxismo analítico. Revista Brasileira de Ciências Sociais, v. 25, n. 73, p. 113-128, jun. 2010.

PERISSINOTTO, R. Marx e a análise contemporânea de classe. In: CODATO, A.; PERISSINOTO, R. Marxismo como Ciência Social. Curitiba: Ed. UFPR, 2011.

PINTO, Á. V. A Sociologia dos Países Subdesenvolvidos. Rio de Janeiro: Contraponto, 2008.

POULANTZAS, N. As classes sociais. Estudos CEBRAP, São Paulo, n. 3, p. 5-39, jan. 1973.

PRZEWORSKI, A. Capitalismo e Social-Democracia. São Paulo: Companhia das Letras, 1989. 
Ed. UFMG, 2002.

THERBORN, G. Do Marxismo ao Pós-Marxismo? São Paulo: Boitempo, 2012a.

THERBORN, G. Class in the 21st Century. New Left Review, v. 5, n. 87, p. 5-29. 2012b.

THOMPSON, E. P. A Formação da Classe Operária Inglesa. Rio de Janeiro: Paz e Terra, 1987.

WILLIS, P. Aprendendo a ser trabalhador: escola, resistência e reprodução cultural. Porto Alegre: Artes Médicas, 1991.

WRIGHT, E. O. Class Counts: comparative studies in class analysis. Cambridge: Cambridge University Press, 1997.

WRIGHT, E. O.; LEVINE, A.; SOBER, E. Reconstruindo o Marxismo. Petrópolis: Vozes, 1993.

Artigo:

Recebido em: 17/09/2013

Aceito em: 16/12/2013 